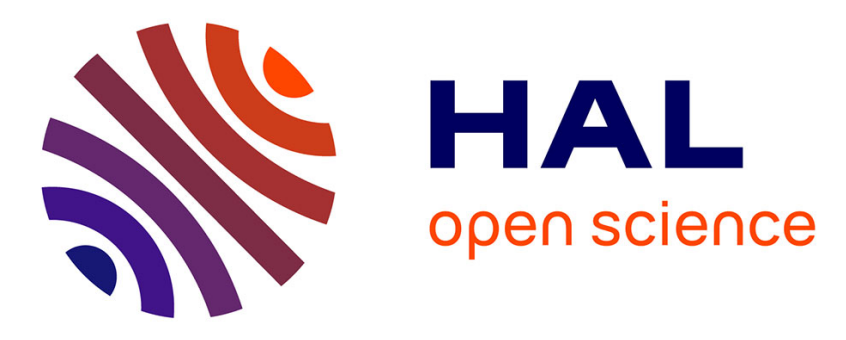

\title{
The contribution of bioenergy to the decarbonization of transport: a multi-model assessment
}

\author{
Florian Leblanc, Ruben Bibas, Silvana Mima, Matteo Muratori, Shogo \\ Sakamoto, Fuminori Sano, Nico Bauer, Vassilis Daioglou, Shinichiro Fujimori, \\ Matthew J Gidden, et al.
}

\section{To cite this version:}

Florian Leblanc, Ruben Bibas, Silvana Mima, Matteo Muratori, Shogo Sakamoto, et al.. The contribution of bioenergy to the decarbonization of transport: a multi-model assessment. Climatic Change, 2022, 170 (3-4), 10.1007/s10584-021-03245-3 . hal-03558507

\section{HAL Id: hal-03558507 https://hal.science/hal-03558507}

Submitted on 4 Feb 2022

HAL is a multi-disciplinary open access archive for the deposit and dissemination of scientific research documents, whether they are published or not. The documents may come from teaching and research institutions in France or abroad, or from public or private research centers.
L'archive ouverte pluridisciplinaire HAL, est destinée au dépôt et à la diffusion de documents scientifiques de niveau recherche, publiés ou non, émanant des établissements d'enseignement et de recherche français ou étrangers, des laboratoires publics ou privés. 
1 The contribution of bioenergy to the

2 decarbonization of transport: a multi-

\section{3 model assessment}

4 Florian Leblanc ${ }^{1}$, Ruben Bibas ${ }^{1}$, Silvana Mima ${ }^{2}$, Matteo Muratori ${ }^{3}$, Shogo Sakamoto ${ }^{4}$, Fuminori 5 Sano $^{5}$, Nico Bauer ${ }^{6}$, Vassilis Daioglou ${ }^{7,8}$, Shinichiro Fujimori ${ }^{9}{ }^{10}$, Matthew J. Gidden ${ }^{11,12}$, 6 Estsushi Kato ${ }^{13}$, Steven K Rose ${ }^{14}$, Junichi Tsutsui ${ }^{5}$, Detlef P van Vuuren ${ }^{7,8}$, John Weyant ${ }^{15}$, 7 Marshall Wise ${ }^{16}$

${ }^{1}$ International Research Center on the Environment and Development (CIRED), Nogent-sur-Marne, France

${ }^{2}$ GAEL, CNRS, Grenoble INP, INRA, Univ. Grenoble Alpes, 38400 Saint Martin d'Hères, France

${ }^{3}$ National Renewable Energy Laboratory (NREL), Golden, Colorado, United States of America

${ }^{4}$ Central Research Institute of Electric Power Industry, Japan

${ }^{5}$ Research Institute of Innovative Technology for the Earth 9-2, Kizugawadai, Kizugawa-shi, Kyoto, 6190292 Japan

${ }^{6}$ Potsdam Institute for Climate Impact Research (PIK), Potsdam, Germany

${ }^{7}$ Copernicus Institute of Sustainable Development, Utrecht University, Princetonlaan 8a, 3584 CB Utrecht

${ }^{8}$ PBL Netherlands Environmental Assessment Agency, P.O. box 30314, 2500 GH The Hague, The Netherlands

${ }^{9}$ Department of Environmental Engineering, Kyoto University, C1-3 361, Kyotodaigaku Katsura, Nishikyoku, Kyoto city, Japan

${ }^{10}$ National Institute for Environmental Studies, Center for Social and Environmental Systems Research,

Tsukuba, Ibaraki 305-8506, Japan

${ }^{11}$ Climate Analytics, Berlin, Germany

${ }^{12}$ International Institute for Applied Systems Analysis, Laxenburg, Austria

${ }^{13}$ Institute of Applied Energy (IAE), Minato, Tokyo 105-0003, Japan

${ }^{14}$ Energy Systems and Climate Analysis Research Group, Electric Power Research Institute (EPRI), Washington, DC, USA

${ }^{15}$ Stanford University, Stanford, CA, USA

${ }^{16}$ Joint Global Change Research Institute, Pacific Northwest National Laboratory and the University of Maryland, College Park, USA

\section{Corresponding Author:}

Florian Leblanc

Email: florian.leblanc@ centre-cired.fr

Tel: +33143947396

ORCID: 0000-0001-9154-5847 


\title{
38 \\ The contribution of bioenergy to the \\ 39 decarbonization of transport: a multi- \\ 40 model assessment
}

41

42

43

44

45

46

47

48

49

50

51

52

53

54

55

56

57

58

59

60

61

62

63

64

65

66

67

68

69

70

\begin{abstract}
The expected growth in the demand for mobility and freight services exacerbates the challenges of reducing transport GHG emissions, especially as low-carbon alternatives to petroleum fuels are limited for shipping, air and long-distance road travel. Biofuels can offer a pathway to significantly reduce emissions from these sectors, as they can easily substitute for conventional liquid fuels in internal combustion engines. In this paper we assess the potential of bioenergy to reduce transport GHG emissions through an integrated analysis leveraging various assessment models and scenarios, as part of the $33^{\text {rd }}$ Energy Modeling Forum study (EMF-33). We find that bioenergy can contribute a significant, albeit not dominant, proportion of energy supply to the transport sector: in scenarios aiming to keep the temperature increase below $2{ }^{\circ} \mathrm{C}$ by the end of the $21^{\text {st }}$ century, models project that bioenergy can provide in average $42 \mathrm{EJ} / \mathrm{yr}$ (ranging from 5 to $85 \mathrm{EJ} / \mathrm{yr}$ ) in 2100 for transport (compared to $3.7 \mathrm{EJ}$ in 2018), mainly through lignocellulosic fuels. This is $9-62 \%$ of final transport energy use. Only a small amount of bioenergy is projected to be used in transport through the electricity and hydrogen pathways, with a larger role for biofuels in road passenger transport than in freight. The association of carbon capture and storage (CCS) with bioenergy technologies (BECCS) is a key determinant in the role of biofuels in transport, because of the competition for biomass feedstock to provide other final energy carriers along with carbon removal. Among models that consider CCS in the biofuel conversion process the average market share of biofuels is $21 \%$ in 2100 , compared to $10 \%$ for models that do not. Cumulative direct emissions from the transport sector account for half of the emission budget (from 300 to 670 out of $1,000 \mathrm{GtCO}_{2}$ ). However, the carbon intensity of transport decreases as much as other energy sectors in 2100 when accounting for process emissions, including carbon removal from BECCS. Lignocellulosic fuels become more attractive for transport decarbonization if BECCS is not feasible for any energy sectors. Since global transport service demand increases and biomass supply is limited, its allocation to and within the transport sector is uncertain and sensitive to assumptions about political as well as technological and socioeconomic factors.
\end{abstract}

\section{Keywords}

Bioenergy, Transport sector, Lignocellulosic fuels, Climate mitigation, Integrated Assessment Models 


\section{Introduction}

Mitigation of climate change requires the reduction of greenhouse gas emissions (GHG) in every economic sector, including transport, which today relies heavily on petroleum fuels and accounts for $23 \%$ of global energy sector emissions (IEA, 2020a; Victor et al., 2014). Decarbonization of transport is challenging (Rogelj et al., 2018; Sims et al., 2014) due to the rapid growth in global passenger and freight service demand and limited alternatives to liquid petroleum fuels. Switching to low-carbon fuels is one option for GHG emission reduction in transport, among which biomass constitutes a versatile energy carrier that can provide various low-carbon transport fuels: liquids, gases, electricity or hydrogen. Moreover, further emission reduction can be achieved when bioenergy is combined with carbon capture and storage (BECCS) for all these energy carriers (Muratori et al., 2020a; Azar et al., 2010). Liquid biofuels are a convenient solution for transport decarbonization: biofuels can be integrated with the existing infrastructure and end-use technologies, offering a solution to incrementally lower the emission intensity of the current vehicle fleet ${ }^{1}$ or in sub-sectors that currently do not have any cost-effective alternative to liquid fuels such as freight (Muratori et al., 2017b), maritime, and air transport ${ }^{2}$. However, compared with the current demand for transport services as well as other final energy demands and the prospect of substantial future growth, the total potential of biomass supply is limited. This makes the allocation of bioenergy to and within the transportation sector a crucial question in the context of climate change mitigation.

Significant progress has been made in developing effective and cost-competitive biofuel production. Firstgeneration biofuels, involving the conversion of sugar, starch or vegetable oil from food crops, represented 4\% (79 Mtoe) of the road transport energy mix in 2016 (IEA, 2017). Second-generation biofuels (including lignocellulosic fuels) involve advanced bioenergy technologies (ABTs) to produce liquid fuels. First and second-generation biofuels can be coupled with carbon capture and storage (CCS) to provide negative emissions (Cheah et al., 2016; Johnson et al., 2014; Muratori et al., 2017a). Because existing facilities are currently at an experimental stage, future costs of biomass production and bioenergy feedstock are difficult to evaluate ( $\mathrm{Li}$ et al., 2018; Fuss et al., 2018). However, lignocellulosic fuels are likely to provide the largest market share of future biofuels (IEA, 2017). Compared to firstgeneration biofuels, second-generation biofuels provide greater GHG emission reductions (Daioglou et al., 2017; Macedo et al., 2014). Also, their indirect impact on land-use GHG emissions and food prices can be limited if energy crops are grown on marginal and abandoned land, or if the biomass feedstock comes from managed forests, residues and waste (Havlík et al., 2011).

Biofuels played a prominent role in previous transport decarbonization mitigation scenarios, depending on the one hand on competition with other low-carbon fuels and on the other on the value of biomass feedstock for carbon removal through BECCS in any energy sector. The EMF-27 study (Rose et al., 2014) of specific materials for dedicated engines or selling flexible fuels vehicles (Kavitha and Vijayasarathi, 2015; Sorate and Purnanand, 2015; Du et al., 2013; Singh et al., 2012).

2 See Hileman and Stratton (2014) for a review of alternative jet fuels, Why et al. (2019) and Wei et al. (2019) for a specific review of alternative jet fuels including biojet fuels. See Wise et al. (2017) for an integrated assessment of the role of biojet fuels in mitigation pathways. The role of biomass in low-carbon marine transport compared to other technological alternatives is described in Tanzer et al. (2019), Taljegard et al. (2014) and TFI (2018). 
106 shows a regional biofuel market share in transport of up to 70\%, with the higher levels occurring in OECD countries and Asia, within a set of harmonized mitigation scenarios comparing several integrated assessment models (IAMs). Ahlgren et al. (2017) conduct a literature review of global energy-economy scenarios and report the biofuel market share in transport to be as high as $40 \%$. In IEA (2017), a scenario aiming at stabilizing temperature increase at well below $2^{\circ} \mathrm{C}$ shows that biofuels contribute $36 \%$ of emissions reduction in transport, compared to $15 \%$ for electricity. Increasing the climate policy stringency from $2^{\circ} \mathrm{C}$ to $1.5^{\circ} \mathrm{C}$ in IAMs scenarios results in increased use of biofuels and a roughly constant share of electricity use in transportation (Rogelj et al., 2015). This saturation of transport electrification for the well-below $2^{\circ} \mathrm{C}$ target can be explained by model assumptions, for example, the lack of electric transportation end-use alternatives (e.g. electric trucks) in IAMs (Muratori et al., 2020b). A Recent IAM study with a linkage to a bottom-up transport model shows increasing electrification of passenger transport when comparing the $2^{\circ}$ and $1.5^{\circ} \mathrm{C}$ scenarios (Zhang et al., 2018). Higher electrification rates in scenarios are generally associated with a reduced share of biofuels in transport, except in freight (Zhang et al., 2020; McCollum 2014). However, without actions to support widespread EV adoption biofuels might remain a relevant low carbon alternative for on-road transport (McCollum et al. 2017), and biofuel blending rate standards could come as a complement to EV adoption policies (Mercure et al. 2018).

The main objective of this paper is to assess the potential contribution of biomass to the deep decarbonization of the transport sector, leveraging different models in a consistent scenario framework focusing on climate change mitigation and the role of Advanced Bioenergy Technologies (ABTs). In particular, we answer the following questions: what is the role of bioenergy in the future transport energy mix, through which final energy carrier, and how does it help to reduce transport emissions compared to other energy sectors? We evaluate scenarios aiming to limit the temperature increase to well below $2^{\circ} \mathrm{C}$ in 2100 with 10 global IAMs that use dedicated land-use models. The cost-effectiveness analysis provided by IAMs is equivalent to assuming coordination of strategies between the different energy sectors in order to minimize mitigation costs to achieve a climate stabilization target. These IAM scenarios inform the tradeoffs in the distribution of mitigation efforts across sectors. In particular, we evaluate bioenergy's role in transport decarbonization from two perspectives: inter-sectorial competition for biomass feedstock, including the role of BECCS, and the competition between different fuels to decarbonize transportation. We account for direct as well as indirect emissions from fuel production in order to emphasize the role of transport in triggering carbon removal. This paper is part of, and leverages results from, the EMF-33 project (Rose et al., 2020), which assesses the emission reduction potential of bioenergy from the supply and demand sides. This paper therefore also contributes to increasing transparency by providing insight into how the different modelling assumptions can be linked to the results in the transportation sector.

140 The paper is structured as follows. Section 2 presents the methodology, the scenario design and model 141 assumptions. Section 3.1 describes the different pathways through which bioenergy enters the transport energy mix under a stringent climate objective, as well as the role of CCS. Section 3.2 discusses the competition of lignocellulosic fuels with hydrogen and electricity for the case of road transport. Section 3.3 analyzes the role of bioenergy in reducing transport emissions when considering process emissions from fuel production, including negative emissions from BECCS. Section 4 discusses our results with respect to the recent trend in transport electrification. Section 5 concludes. 


\section{Methods}

\subsection{EMF-33 transportation modeling}

149

This paper presents simulation results from the demand phase of the EMF-33 modelling exercise, which focuses on the role of ABTs for climate mitigation scenarios (Rose et al. 2020; Bauer et al., 2018). Ten IAMs produced results to evaluate three climate policy scenarios described below. All models are multi-regional with global coverage, designed to evaluate long-term mitigation pathways; most of them have already participated in several model comparison exercises (Marangoni et al., 2017, Riahi et al. 2017; Kriegler et al. 2014; Rose et al. 2014; Clarke et al., 2014). This section describes the modelling of transport, while several companion papers provide additional information: Bauer et al. (2018) describe EMF-33 bioenergy demand scenarios regarding stringent climate targets and the availability of the different ABTs; Daioglou et al. (2020) highlight the role of technological cost assumptions in driving scenario results; Muratori et al. (2020a) highlight the role of BECCS with respect to the various bioenergy carriers; Rose et al. (this issue) evaluate the supply of biomass feedstock with respect to the modelling of land-use in the different IAMs.

The differences in model assumptions are summarized in Table 1. Half of the models are recursive-dynamic, the other half being solved with an inter-temporal optimization procedure. Almost all the models provide an endogenous representation of the demand for passenger travel (8/10) with half including modal shift (5/10). Fewer models include an endogenous representation of freight (6/10) and fewer still include modal shift (3/10). Besides modal shift, emission reductions in IAMs are mainly achieved through fuel switching and energy efficiency measures in contrast to more flexible demand measures as depicted by scenarios evaluated with bottom-up transport models (Gota et al., 2018; Edelenbosch et al., 2017; Yeh et al. 2017). Our analysis does not focus on the role of additional policies aiming to accelerate technology diffusion, which are for example an important driver of transport electrification (McCollum et al., 2017; Mercure et al., 2018), beyond those included implicitly or explicitly in the models. For example, the REMIND model considers optimal subsidies for low-carbon technologies which allow for an acceleration of the learning phase (Schultes et al., 2018).

The variety of assumptions across models regarding the availability of ABTs allows us to obtain insight into the role of the different bioenergy pathways and CCS in driving transport emission reduction. Some models include synthetic gases from biomass ${ }^{3}$, and all models except one (BET) include first generation biofuels, however with limited growth potential (see section A.3 of the SOM). All models consider CCS with the production of electricity ( $E$ ) from bioenergy, while only eight models consider the production of hydrogen (H) from biomass (six with CCS). Finally, all models incorporate lignocellulosic fuel ${ }^{4}$ (LC) production and six have the upgrade that includes CCS. The penetration of low-carbon technologies into IAMs depends on the way end-use technologies or fuels compete with each other within each energy sector (Bauer et al., 2018). The competition of lignocellulosic fuel with other energy carriers in transport is modelled by multinomial

Through gaseification or anaerobic digestion of biomass feedstocks.

4 The lignocellulosic fuel conversion process may concerns biochemical or thermochemical conversion or both, depending on the assumptions of each models. See Table A.7 in the SOM. 
logits for half of the models (AIM/CGE, GCAM, IMACLIM-NLU, IMAGE, POLES) and with more flexible systems for the other half (BET, DNE21+, REMIND-MAGPIE, GRAPE-15, MESSAGE-GLOBIOM). Finally, some models endogenously represent vehicle costs $(4 / 10)$ and vehicle efficiency $(2 / 10)$.

\subsection{The scenario protocol}

All scenarios assume costs and the availability of non-ABTs as considered in the Baseline, which includes conventional technologies as well as renewable energies as commonly assumed in IAMs $^{5}$. The Baseline scenario is calibrated so as to reflect the SSP2 narrative in terms of GDP and population (Riahi, 2017). A diagnostis of the EMF-33 harmonization procedure with respect to several indicators (population, GDP, final energy) can be found in the overview paper (Bauer et al., 2018) and the corresponding supplementary materials ${ }^{6}$.

Apart from the Baseline we evaluate three climate sensitivity scenarios using an intertemporal carbon budget constraint of 1,000 $\mathrm{GtCO}_{2}$ over the period 2011-2100 which account for $\mathrm{CO}_{2}$ emissions from fossil fuels and industries (FFI) net of carbon dioxide removal from BECCS. This emissions budget is indicative for a $67 \%$ chance of limiting global surface temperature increase to below $2^{\circ} \mathrm{C}$ (Rogelj et al., 2016; IPCC, 2013). Some models (AIM/CGE, DNE21+, GCAM, GRAPE-15, IMAGE, MESSAGE-GLOBIOM) assume that afforestation is capturing $\mathrm{CO}_{2}$ from the atmosphere in response to the carbon price, but this does not affect the carbon budget considered from FFI. Apart from BECCS and afforestation, no other negative emissions technologies are considered by models. A set of sensitivity scenarios with a higher emission budget $(1,600$ $\mathrm{GtCO}_{2}$ ) is also discussed in the SOM. Baseline and climate policy scenarios are calibrated so as to reflect near-term climate policies, including the Cancun pledges or National Determined Contributions (NDCs) for 2020. The set of climate sensitivity scenarios concerns three technological variants which emphasize the role of lignocellulosic fuel on the one hand, and the role of CCS technology in decarbonizing transport on the other:

- a scenario in which the full set of ABTs is available ('full')

- a scenario in which the lignocellulosic conversion route is not available ('nofuel')

- a scenario which serves to assess the role of lignocellulosic fuels when CCS (BECCS) is not available for any bioenergy transformation pathway ('nobeccs').

The carbon budget is implemented after 2020 in each model (Table 1). Beside emission or budget constraints, five models out of ten use a carbon tax on FFI emissions, which determines the cost-effective choice of the transport energy mix regarding emission intensities and system flexibility in switching between technologies. Policy implementation also drives the allocation of biomass feedstock across the different energy sectors so as to minimize total policy cost, at each time-step for recursive dynamic models or for the whole period in inter-temporal optimization models. The carbon price resulting from the policy

\footnotetext{
5 https://www.iamcdocumentation.eu/index.php/IAMC_wiki

6 https://static-content.springer.com/esm/art\%3A10.1007\%2Fs10584-018-2226-y/MediaObjects/10584_2018_2226_MOESM1_ESM.docx

7 The full set of ABTs includes the production of hydrogen and electricity from biomass, as well as lignocellulosic fuels.
} 
constraint in each model is applied to emissions from agriculture, forestry, and other land uses ${ }^{8}$, thus avoiding emission leakages towards the land-use sector. The competitiveness of bioenergy with other lowcarbon fuels then also depends on the value of GHG emissions which is reflected in the biomass feedstock supply costs, as accounted for by each respective land-use model (Rose et al., this issue). The inclusion of land-use based mitigation measures in response to carbon pricing in some models, such as avoided deforestation and afforestation/reforestation, isare likely to influence the availability of biomass feedstock and its emission intensity. Section A.7 in the SOM further discusses the indirect role of land use in transport mitigation and checks that cumulative induced emissions from the land-use sector do not outweigh emissions savings in FFI thanks to bioenergy.

\section{Results}

\subsection{Bioenergy in the transport energy mix and the role of CCS}

Without climate policy, bioenergy can still reduce GHG emissions in transport if it substitutes for petroleum-based fuels to a sufficient degree. The Baseline scenarios show the average transport sector final energy to be $219 \mathrm{EJ} / \mathrm{yr}$ in 2100 (ranging from 193 to $263 \mathrm{EJ} / \mathrm{yr}$, Fig. 1), an increase of 80\% over today's figure compared to an overall increase in energy of $92 \%$. The transport sector remains dependent on carbon-intensive fuels: the energy mix is projected to continue to rely heavily on petroleum-based fuels until 2050 and beyond (between 27 and 88\% of total final energy in 2100), with substitution over time mainly by fossil-fuel-based alternatives (gas-to-liquids for POLES; coal-to-liquids for IMACLIM-NLU and REMIND-MAGPIE; gases for GCAM), driven by the relative increase in the oil price compared to coal and natural gas (see Figs. A1 and A2 in SOM). The role of hydrogen and electricity is limited ( $9 \%$ on average for electricity, $23 \%$ at most for MESSAGE-GLOBIOM), and the production of those two energy carriers remains carbon-intensive in the baseline scenario. Bioenergy enters the energy mix for transport services via liquid fuels, but only three models show significant shares $(23 \%, 25 \%$ and $26 \%$ for POLES, GRAPPE- 15 and AIM/CGE respectively), giving lignocellulosic fuel a limited role in reducing transport emissions in the Baseline scenario without additional policies such as biofuel mandates or carbon pricing.

The phase-in of biofuels in Baseline scenarios is mostly driven by increasing oil prices and competitiveness of alternatives to the internal combustion engine. However, the use of bioenergy to decarbonize transport under the climate constraint not only depends on cost competitiveness with other transport low-carbon technologies but also on the competition for biomass feedstock with other energy sectors (Daioglou et al., 2020). IAM assessments show that negative emissions associated with bioenergy production significantly lower mitigation costs, so that from a cost-effectiveness perspective, biomass is more valuable in energy conversion processes that can be up-graded with CCS (Muratori et al., 2020a, Bauer et al., 2018, Rose et al. 2014). All models in EMF-33 assume CCS to be available with electricity production from biomass. Consequently, in our climate sensitivity scenario with the full set of technologies available ('full'), lignocellulosic fuels are the predominant low-carbon alternative to petroleum fuels in only five models out of ten in 2100 , among which four assume CCS to be available in the conversion process. 
Our results suggest that the role of bioenergy for transport mitigation is strongly dependent on the feasibility of CCS in the lignocellulosic conversion process if BECCS exists for other energy sectors. Biomass feedstock is preferentially directed towards electricity generation to provide negative emissions in models that do not assume the CCS upgrade for lignocellulosic production (see the BET and DNE21+ models) ${ }^{9}$, with an exception for IMACLIM-NLU. Moreover, the use of biomass in transport increases in comparison to Baseline only in models with the CCS upgrade in lignocellulosic production, with an average market share of $21 \%(2.3-40 \%)$ compared to $10 \%(0-30 \%)$ for models that do not include CCS. Looking at EMF-33 scenarios, Daioglou et al. (2020) show the importance of revenues from carbon sequestration in lowering the LCOEs of bioenergy technologies. Most models exhibit technical costs reduction through learning, which is in some cases compensated by the increase of the cost of biomass feedstocks function of the the demand for bioenergy. However, models with the lowest LCOEs are the one with the highest capture rates due to the role of revenues from carbon sequestration.

Besides the availability of CCS, the absolute level of biofuels depends on the various technical assumptions taken by models. Optimistic assumptions regarding the future development of non-biomass renewable technologies in the power sector strongly influence the availability of biomass for liquid fuels production, part of which is consumed by transports. From a supply-side perspective regarding EMF-33 scenarios, Bauer et al. (2018) found a more balanced allocation of biomass between liquids and electricity production in models with stricter constraints on the deployment of non-biomass renewables. On the demand side, the absolute level of biofuels consumed by transport depends on end-use technology adoption and costs as well as assumed by models, as well as the relative evolution of fossil fuel prices. The absolute level of biofuel use reflects the end-use competition from low-carbon alternatives of the Baseline ${ }^{10}$ : models with a high share electricity, hydrogen or gases in Baseline (GCAM, MESSAGE-GLOBIOM, IMAGE) have a lower share of lignocellulosic liquid fuels in the policy scenario; models with a high share of biofuels in the Baseline scenario or relying on fossil-based alternatives include a higher share of biofuels in the mitigation scenario (from 26 to $57 \%)^{11}$. In comparison, Ahlgren et al. (2017) and Rose et al. (2014) found respectively the largest market share to be $40 \%$ and $70 \%$ for liquid biofuels.

The recourse to negative emissions in mitigation strategies raises concerns about the uncertain feasibility of BECCS, both regarding the technology itself and numerous externalities (Low and Schäfer, 2020; Stoy et al., 2018). Yet if BECCS is not feasible or if CCS were to be deployed at a slower rate than expected, the value of biomass will depend more heavily on its ability to lower GHG emissions in each respective energy sector than on the requirement to provide carbon removal in any particular energy sector. In our sensitivity scenarios without BECCS ('nobeccs') biomass become more valuable in providing lignocellulosic fuels to decarbonize transport with an increased market share for seven models compared to the 'full' scenario (for the $1,600 \mathrm{GtCO}_{2}$ budget scenario ${ }^{12}$, see Fig. A5 and Table A.3 in SOM). Without BECCS, less biomass is directed towards non-liquid energy carriers (electricity, hydrogen, gases) in favor of lignocellulosic fuel

9 Two other models do not consider CCS with lignocellulosic fuel production, leading to different behaviors: the GRAPE-15 model achieve transport decarbonization by using first-generation biofuels, whose feedstocks are not in competition for electricity generation (See section A.3 in SOM for the distinction between first-and second-generation biofuel in transport across models); the IMACLIM-NLU model is the only exception in using lignocellulosic fuels in transport even without CCS. In this model, the cross-sectoral allocation of biomass is not performed using a cost-effectiveness approach, but independently, in response to the biomass feedstock market price (Leblanc et al., this issue).

10 Biofuels for transport are also in competition with other uses, as in the IMAGE model, in which they are produced with CCS but destined for industrial energy use and to some extent for electricity production.

11 The GCAM model also has a high share of biofuels (38\%) in the 'hi' policy scenario, whereas it relies on petroleum fuels and gases in its Baseline scenario.

12 Only few models found the 'nobeccs' scenario to be feasible for the $1,000 \mathrm{GtCO}_{2}$ target, so in the $\mathrm{SOM}$ we present a scenario with a $1,600 \mathrm{GtCO}$ emission budget to discuss sensitivity with respect to BECCS availability. 
production, which is also illustrated by models which do not consider the CCS upgrade for lignocellulosic production: in DNE21+ for example, large quantities of lignocellulosic fuel are allocated to the transport sector at the expense of the decarbonization of the power sector when BECCS are not available. Furthermore, the scenario without lignocellulosic fuels ('nofuel') shows that in some models (POLES, REMIND-MAGPIE, IMACLIM-NLU) the release of biomass supplies for power generation with carbon removal compensates for emissions from increased used of oil in transport. In this scenario, one model (GRAPE-15) exhibits the same level of biofuels demand in transport compare to the 'full' scenario since in both cases it involves the production of first generation biofuels.

\subsection{Competition between lignocellulosic fuel and electricity \& hydrogen}

Considering all pathways, bioenergy accounts on average for $42 \mathrm{EJ} / \mathrm{yr}$ (between 5 and $85 \mathrm{EJ} / \mathrm{yr}$ ) in the transport energy mix. Although biomass is mostly used in transport via liquid fuels, bioenergy can also enter the transport energy mix indirectly through electricity, hydrogen and gases (aggregated in light green in Fig. 1). The amount of bioenergy used in transport via those pathways is rather small for all models (from 0.9 to $10.3 \mathrm{EJ} / \mathrm{yr}$ in the 'full' scenario, Table A.2) due to competition with other low-carbon technologies in each energy market. The use of biomass in transport through these three energy carriers increases in the 'nofuel' scenario when the lignocellulosic liquid fuel conversion route is not available relatively to the 'full' scenario (from 2.6 to $32.5 \mathrm{EJ} / \mathrm{yr}$ in the 'nofuel' scenario) and decreases if BECCS is not feasible ('nobeccs') except for the GCAM model (19.3 EJ/yr).

Competition between biofuel and hydrogen \& electricity varies across transport sub-sectors. Fig. 2 presents the energy mix of road transport broken down between freight and passenger, for five selected models. Road transport accounts for $74 \%$ of transport GHG emissions today (IEA, 2019). For most models, biofuels compete with conventional liquid fuels (mostly petroleum) in freight, and with hydrogen or electricity for on-road passenger transport. The contribution of bioenergy to transport emission reduction is greater in freight than in passenger transport due to more limited alternatives to liquid fuels: the potential for electrification is greater for road passenger than freight services, because of shorter distances driven and the assumed difficulty of electrifying trucks (Nadel, 2019). The unavailability of lignocellulosic fuels ('nofuel') then results in a decrease in freight services for three models (IMACLIM-NLU, GCAM and to a lesser extent POLES, which shows higher potential for hydrogen, likely due to technological progress regarding vehicle costs and efficiency). This result agrees with previous studies highlighting the difficulty of mitigating GHG emissions outside on-road passenger transport (Muratori et al., 2017b), in which electricity and hydrogen are easier to use, thus allowing biofuel to be used in the freight transport sector instead. For example, the IMAGE model shows the greatest potential as being in on-road passenger transport electrification, resulting in a smaller role for biofuels in this subsector. In the DNE21+ and BET models, onroad transport services decrease more significantly because the limited supply of biomass feedstock is directed towards the power sector. If CCS were not to be adopted in the lignocellulosic conversion process, because of technological barriers in the upcoming decades or because of its lower capture rate compare to other BECCS technologies, our results suggest that the more the mitigation strategy relies on BECCS, the stronger the policy incentive to target the development of end-use technologies based on electricity and hydrogen in transport subsectors would need to be. 
Fig. 2.a shows the share of transport emissions in the $1,000 \mathrm{GtCO}_{2}$ emission budget, for the 'full' scenario. Direct $\mathrm{CO}_{2}$ emissions from combustion for transport (solid lines) range from 300 to $670 \mathrm{GtCO}_{2}$ across models, which is about half of the $\mathrm{CO}_{2}$ emissions budget. On average, the transport sector accounts for $23 \%$ of total final energy in 2100, but the contribution in total emission reductions (compared to the Baseline in 2100 ) is rather small (15\% on average, Table A.6). This result agrees with previous IAM studies highlighting the difficulty of decarbonizing transport compared to other energy sectors (Rogelj et al., 2018; Muratori et al. 2017b; Rogelj et al., 2015; Clarke et al., 2014). The first reason is the limited availability of low-carbon alternatives to liquid fuels in non-terrestrial transport and on-road freight. Also the cost-effectiveness approach used in scenarios tends to prioritize the decarbonization of sectors with lower mitigation costs. A third reason is that some IAMs lack the dedicated transport policies which could lead to further emission reductions (Creutzig et al., 2015).

We now look at whether lignocellulosic fuels help to intensify the decrease in the emission content of transport final energy, compared to other energy sectors. Fig. 3.b shows the variation of the emissions intensity compared to Baseline in the transport sector versus the rest of the energy sector in 2100 for two scenarios ('full': end of line with symbol; 'nofuel': end of line without symbol ${ }^{13}$ ). All scenarios are above the black line, meaning the reduction in transport emission intensity is lower than for other energy sectors in 2100. However, for most models the availability of lignocellulosic fuels results in an increase in transport decarbonization. For two models (IMACLIM-NLU, REMIND-MAGPIE), this allows emissions to be shifted to other energy sectors due to limits in the supply of biomass, mainly towards the power sector with less carbon removal. On the contrary when BECCS technologies are not available (Fig. 3.c; 'full': with symbol; 'nobeccs': without symbol), the reduction in transport emission intensity is similar to that of other energy sectors in four models out of five (DNE21+, POLES, REMIND-MAGPIE, IMAGE): without BECCS, biomass becomes highly valuable in the form of liquid fuels for transport.

In the above analysis only direct combustion (tailpipe or tank-to-wheels) emissions are attributed to transport as commonly assumed in IAMs (Rogelj et al. 2018; Luderer et al., 2018; Rogelj et al. 2015). Accounting for fuel-production emissions (well-to-tank) is more relevant for dedicated sectoral studies (Elgowainy et al., 2018; Muratori et al., 2017b; Yeh et al., 2017) especially with scenarios including BECCS. Zhang et al. (2020) show that a significant amount of indirect carbon removal from liquid fuels and electricity production can be attributed to the transport sector. Considering indirect emissions of energy conversion processes (Fig 3.d; 'full': with symbol; 'nofuel': without symbol), transport emission intensity decreases by the same percentage as other energy sectors for four (IMAGE, POLES, REMIND-MAGPIE, IMAGE) of the six models that assume CCS with lignocellulosic fuel production ${ }^{14}$. The strongest decrease is to be found for REMIND-MAGPIE, in which the production of lignocellulosic fuel accounts for $58 \%$ of the transport energy mix in 2100. Regardless of land-use emissions, carbon neutrality could be achieved in transport if liquid fuel BECCS were to account for more than $42 \%$ of the mix (assuming that transport uses only petroleum liquids with $27 \mathrm{kgC} / \mathrm{GJ}$ oil and $-19 \mathrm{kgC} / \mathrm{GJ}$ of carbon removal for lignocellulosic fuels). Among

13

Symbols with no line attached indicate absence of variation.

14 The 'nofuel' scenario is infeasible for AIM/CGE; the GCAM model shows a large decrease in transport emission intensity, but with a larger decrease for the rest of the economy than in other models. 
models that assume CCS, only three reach such market shares for biofuels in 2100 (AIM/CGE, GCAM, REMIND-MAGPIE with $41 \%, 43 \%$ and $58 \%$ respectively).

\section{Discussion}

High levels of carbon removal could be achieved indirectly in the transport sector with a higher electrification rate and a high market share of BECCS in the power sector (or equivalently with hydrogen). Section 3.1 shows that only a small amount of bioenergy corresponds to the electrification of transport due to the large scale of power production with other low-carbon technologies and considering the relatively limited supply potential of biomass feedstocks. However, the capture rate of electricity generation (or hydrogen) through biomass gasification is higher than for lignocellulosic fuel production. A higher electrification rate of transport in our scenarios would likely decrease the importance of lignocellulosic fuels and increase the role of bioenergy in transport electrification.

The observed decrease in battery costs during the past decade (Edelenbosch et al., 2018), supported by dedicated policies in many countries, has triggered an unexpected growth in EV sales (EVs accounted for $2.6 \%$ of total car sales in 2019, (IEA, 2020b), the largest contributions being in China, the United States, Europe and Canada). Several IAMs now project that transport electrification will provide a larger contribution to emission reductions compared to previous assessments (Zhang et al., 2020; Edelenbosch et al., 2017; Zhang et al., 2016) and some recent electrification studies predict massive adoption of battery electric vehicles leading to a two-thirds decrease in gasoline and diesel demand in the U.S. by 2050 (Mai et al., 2018).

These recent advances in electrification technologies are not reflected in our study which does not consider complementary measures in transport beyond those already included in each respective model, thus likely underestimating the potential for EV with respect to biofuels and related carbon removal. Batteries and support for electric vehicle charging are opening up for widespread EV adoption and thus increasing opportunities for achieving deep transport decarbonization (Muratori and Mai, 2021; Nadel et al., 2019; Edelenbosch et al., 2017). A broader policy package including the role of consumers in end-use technology may lead to emission reduction in passenger road transport compliant with a $2^{\circ} \mathrm{C}$ target, as shown in Mercure et al. (2018). More generally, policies oriented towards the adoption and diffusion of end-use technologies result in higher electrification rates for transport, contrasting with previous IAM studies (Muratori et al., 2020b; Venturini et al., 2019; Ramea et al., 2018; Mercure et al., 2018; McCollum et al., 2017).

\section{Conclusions}

This study has assessed the role of biomass in reducing transport sector emissions during the $21^{\text {st }}$ century by analyzing a set of harmonized scenarios. In mitigation scenarios, all models project continued reliance on petroleum fuels until 2050 and continued significant use of fossil fuels by 2100 , often offset by negative emissions (mostly from BECCS). Results show that CCS availability is more important in driving biofuel market share in transport than the competition with other low carbon fuels, with, however, a greater role in freight services than in passenger transport because of the relative potential for electricity or hydrogen. 
The diversity of modeling frameworks in the 10 IAMs considered provides general insights into the role of bioenergy in cost-effective transport decarbonization:

Biomass only enters the energy mix in significant quantities for three models in Baseline. The phase-in of biofuels in Baseline scenarios is mostly driven by increasing oil prices and the competitiveness of alternatives to the internal combustion engine.

Lignocellulosic fuel is the predominant bioenergy pathway for transport mitigation. In mitigation scenarios, the use of bioenergy in transport represent $42 \mathrm{EJ} / \mathrm{yr}$ on average (ranging from 5 to $85 \mathrm{EJ} / \mathrm{yr}$ ) in 2100 , mostly in the form of lignocellulosic liquid. Only small amounts of bioenergy are present in transport via electricity or hydrogen because of the limited end-use technologies for long-haul use. The level of lignocellulosic fuels in transport is sensitive to the availability of other low-carbon alternatives in each transport sub-sector, with a greater contribution to freight than to passenger transport.

Lignocellulosic fuels allow for further decrease in transport emission intensity. Cumulative direct emissions from the transport sector account for half of the emission budget (between 300 and 670 of the $1,000 \mathrm{GtCO}_{2}$ ). However, accounting for indirect emissions from fuel conversion processes, including carbon removal from BECCS, the transport carbon intensity decreases as much as other energy sectors.

The availability of CCS is a key determinant of bioenergy's role in transport decarbonization. The production of lignocellulosic fuels, hydrogen and electricity all compete for limited biomass feedstocks. If BECCS technologies are assumed to be feasible, bioenergy is really valuable in providing carbon removal, so that lignocellulosic fuels are attractive for transport decarbonization only on the assumption of an upgrade with CCS. The average market share of biofuels is $21 \%$ in 2100 among models that consider CCS in the biofuel conversion process compared to $10 \%$ for models that do not and where biomass feedstock is directed instead towards electricity generation to provide carbon removal. Like most low-carbon technologies in transport, lignocellulosic fuel requires policies targeted towards R\&D and supporting regulations in order to be deployed on a large scale (Mulholland et al., 2018), and research should consider CCS in the conversion process in order to increase the chance of bioenergy being a plausible low-carbon alternative in transport mitigation pathways.

Lignocellulosic fuels are very attractive for transport decarbonization if BECCS not feasible. Most IAM scenarios assume BECCS in the technological portfolio, which drives biomass usage towards carbon removal regardless of the energy sector. On the contrary, if BECCS is not feasible, biomass is found to be critical in lowering transport emissions with lignocellulosic fuels. In our scenarios, transport emission intensity shrinks by the same percentage as other energy sectors in 2100 when BECCS is not available for any energy carriers.

Several limitations affect the results of our paper and the EMF-33 study. First, only the benefits of using bioenergy for climate change mitigation are considered, whereas the large scale deployment of bioenergy crops raises concerns with respect to several externalities such as induced land-use emissions, food security and prices, water use and the impact on biodiversity (Stoy et al., 2018; Fajardy and Mac Dowell, 2017; Lotze-Campen et al., 2014) or to BECCS technologies themselves (Low, S. and Schäfer 2020; Muratori et al. 2016; Fuss et al. 2014). Even if IAMs often include land-use management measures in order to limit the negative impacts of biomass feedstock production, a deeper analysis of the tradeoffs regarding the use of lignocellulosic fuels and those externalities are likely to limit its attractiveness for mitigating transport emissions. Secondly, the EMF-33 study only consider a carbon budget for fossil fuels and industrial 
emissions, so that only BECCS can contribute negatively to this budget. While afforestation also competes for land with biomass feedstock production, any other negative emissions technologies, such as direct air capture (Realmonte et al., 2019), could contribute to offset residual emissions from the transport sector. Thirdly, we only described the detailed energy mix for road transport as it accounts nowadays for $74 \%$ of transport emissions. Further studies should assess the role of biofuels in the different transport mode, and the optimal allocation across those modes, especially regarding the evolution of international trade and the specific constraints concerning the adoption of bio-kerosene in air transport and the issue of corrosion from bio-based fuels in long distance shipping. Finally, the role of lignocellulosic fuel in mitigating transport emissions should also be assessed considering recent technology trends, especially with respect to electric vehicles, and complementary policies concerning technological adoption (Mercure et al., 2018; McCollum et al., 2017; Pettifor et al., 2017). This research agenda for IAMs includes better representation of sociological and technological factors, and their interactions, that drive transport demand and emissions reduction, modal choices, emerging mobility trends (e.g., telework, ride-hailing) as well as new technologies and business models (Muratori et al. 2020b). The EMF-33 study provides useful scenarios for assessing the role of biofuels in transport, but since the EMF-33 scenarios were designed (Bauer et al. (2018), major changes have occurred with respect to transportation, most notably the rise of electric vehicles (IEA, 2020b), and the sector is evolving rapidly (Mai et al., 2020). Further research should explore the potential role of bioenergy to decarbonize the transport sector with respect to these gaps and limitations.

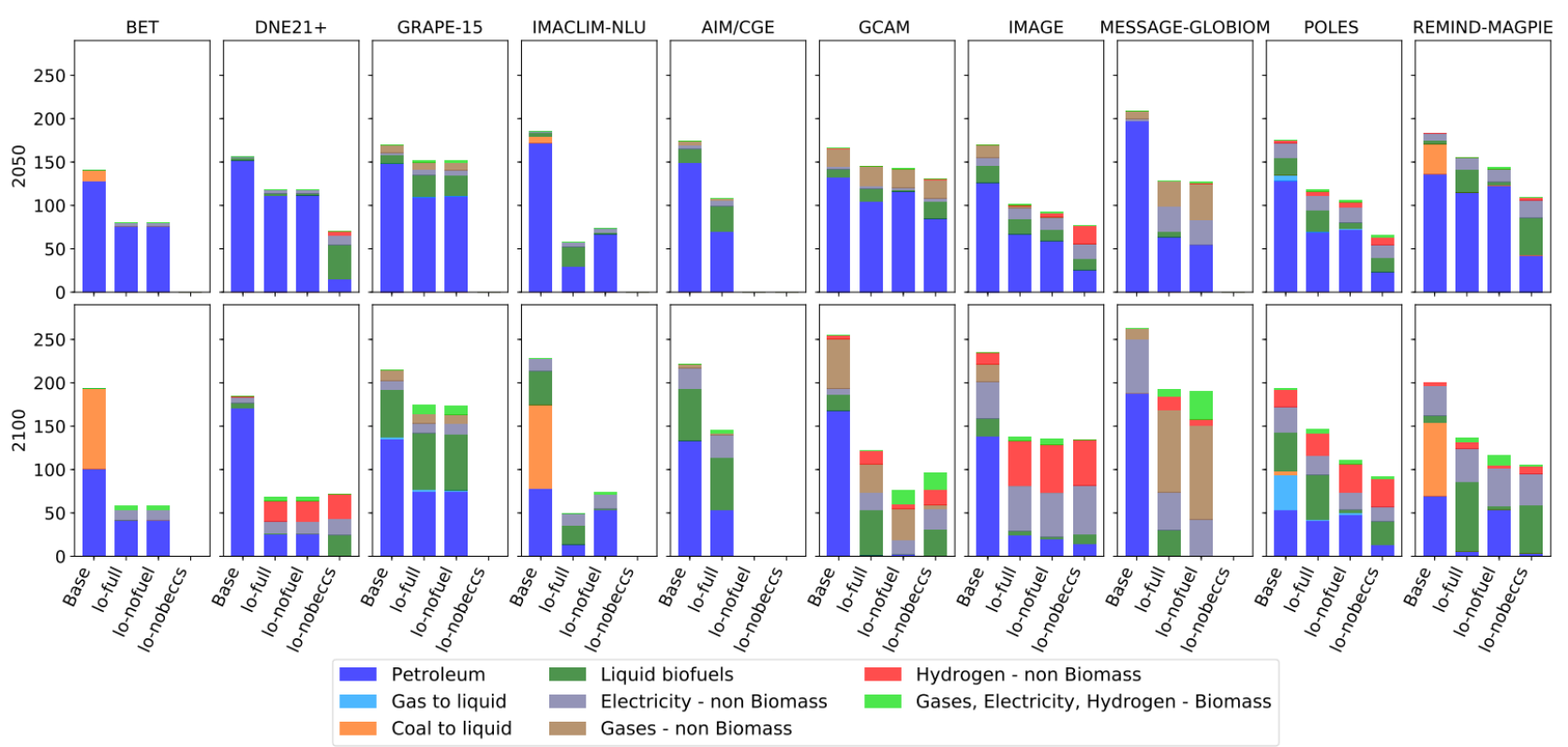

Figure 1: Final energy mix for transport by fuel (EJ/yr) for the different models and scenarios, in 2050 and 2100. Use of bioenergy via hydrogen, electricity and gases is aggregated into a single category (light green). 

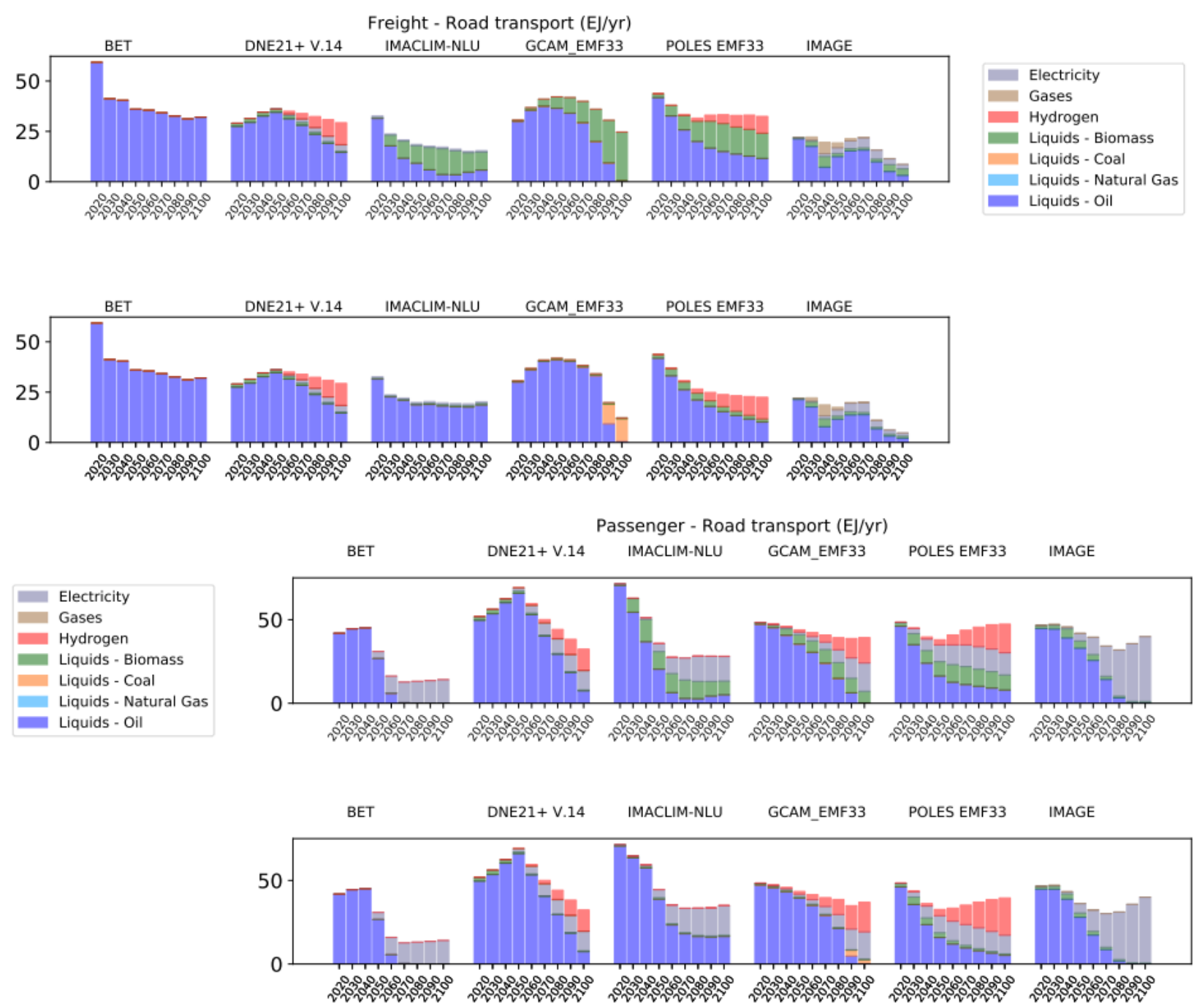

Figure 2: Final energy mix of road transport for freight and passenger mobility (bar chart), for the 'full' (top) and 'nofuel' (bottom) scenarios. The lines indicate final energy trends for the overall passenger and freight modes (not only road). Trends are normalized to the first year. Solid lines indicate the trend of the 'full' scenario, dashed lines the trend of the 'nofuel' scenario. 
(a)

Transport cumulative FFI emissions or Final Energy in \% of Total (2011-2100)

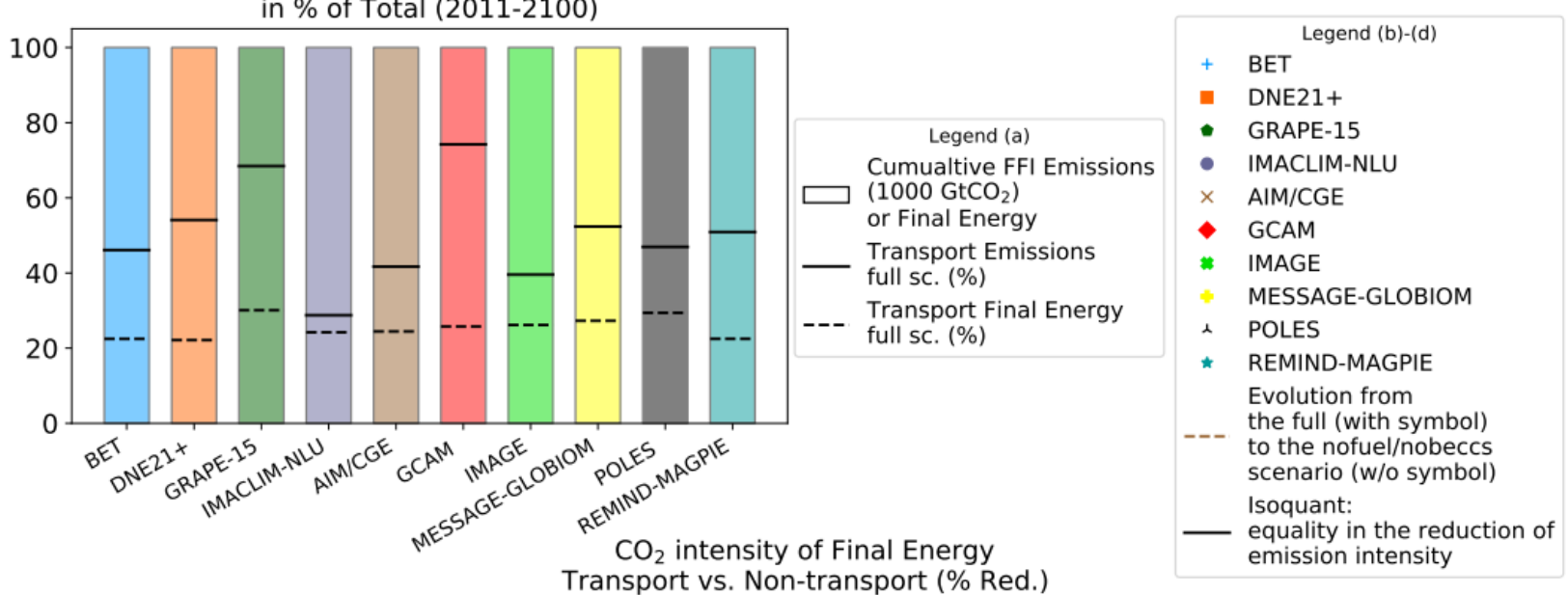

(b) full vs. nofuel

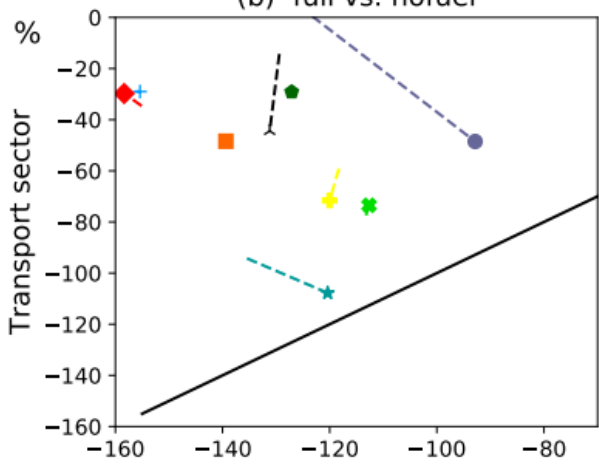

(c) full vs. nobeccs

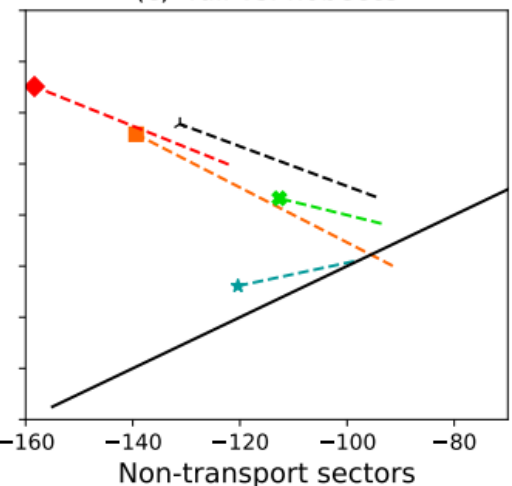

(d) full vs. nofuel (ind.)

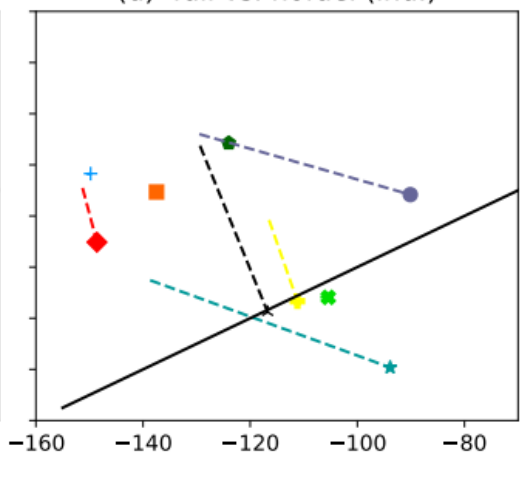

Figure 3: (a) Contribution of transport emissions to the 1,000 GtCO2 cumulative emission budget (solid lines: direct combustion emissions; dashed lines: accounting for emissions from energy conversion processes. (b) Percentage reduction in emission intensities of transport final energy ( $y$-axis) and non-transport final energy (x-axis), in 2100 compared to the baseline. Two scenarios are shown: 'nofuel' (no symbol) and 'full' (with symbol). (c) Percentage reduction in emission intensities of transport final energy for the 'nobeccs' (no symbol) and 'full' scenarios (with symbol). (d) Percentage reduction in emission intensities of transport final energy when accounting for emissions from energy conversion processes, for the 'nofuel' (no symbol) and 'full' scenarios (with symbol). Symbols with no line attached indicate absence of variation. 
Table 1

\begin{tabular}{|c|c|c|c|c|c|c|c|c|c|c|c|}
\hline \multicolumn{2}{|r|}{ Models $^{15}$} & AIM/CGE & BET & DNE21+ & $\begin{array}{l}\text { REMIND- } \\
\text { MAGPIE }\end{array}$ & GCAM & GRAPE-15 & $\begin{array}{l}\text { IMACLIM- } \\
\text { NLU } \\
\end{array}$ & IMAGE & $\begin{array}{l}\text { MESSAGE- } \\
\text { GLOBIOM }\end{array}$ & POLES \\
\hline \multicolumn{2}{|r|}{ General algorithm $^{16}$} & CGE-RD & CGE-IT & PE-IT & CGE-IT & PE-RD & CGE-IT & CGE-RD & PE-RD & PE-IT & PE-RD \\
\hline \multicolumn{2}{|c|}{ Climate policy integration } & $\begin{array}{l}\text { Emission } \\
\text { constraint }\end{array}$ & $\begin{array}{l}\text { Budget } \\
\text { constraint }\end{array}$ & $\begin{array}{c}\text { Budget } \\
\text { constraint }\end{array}$ & Tax & Tax & $\begin{array}{c}\text { Budget } \\
\text { constraint }\end{array}$ & Tax & Tax & Tax & Tax \\
\hline \multirow{4}{*}{$\begin{array}{l}\text { Service } \\
\text { demand }\end{array}$} & $\begin{array}{l}\text { Level of demand-- } \\
\text { passengers }{ }^{17}\end{array}$ & $\mathrm{D}$ & $\mathrm{D}$ & $\mathrm{X}$ & Yes & $\mathrm{D}$ & GDP/cap & $\mathrm{D}$ & $\mathrm{D}$ & $\mathrm{D}$ & $\mathrm{D}$ \\
\hline & $\begin{array}{l}\text { Endogenous passenger modal } \\
\text { shift }\end{array}$ & No & No & No & Yes & Yes & No & Yes & Yes & No & Yes \\
\hline & Level of demand - freight & $\mathrm{D}$ & $\mathrm{D}$ & $\mathrm{X}$ & $\mathrm{D}$ & $\mathrm{D}$ & GDP/cap & $\mathrm{D}$ & $\mathrm{D}$ & $\mathrm{X}$ & $\mathrm{X}$ \\
\hline & $\begin{array}{l}\text { Endogenous freight modal } \\
\text { shift }\end{array}$ & No & No & No & No & $\begin{array}{c}\text { Yes } \\
\text { (Fairly } \\
\text { inelastic) }\end{array}$ & No & Yes & Yes & No & No \\
\hline \multirow{5}{*}{$\begin{array}{l}\text { Fuel and } \\
\text { technology }\end{array}$} & $\begin{array}{l}\text { Bioenergy for Electricity, } \\
\text { Liquids, Hydrogen }^{18}\end{array}$ & $\begin{array}{l}\mathrm{E}+ \\
\mathrm{LC}^{*}+\end{array}$ & $\begin{array}{l}\mathrm{E}^{*+}+ \\
\mathrm{LC}^{*} \\
\mathrm{H}^{*}\end{array}$ & $\begin{array}{l}\mathrm{E}^{*+}+ \\
\mathrm{LC}^{*} \\
\mathrm{H}^{*+}\end{array}$ & $\begin{array}{c}\mathrm{E}+ \\
\mathrm{LC}{ }^{*}+ \\
\mathrm{H}+\end{array}$ & $\begin{array}{c}\mathrm{E}^{*+} \\
\mathrm{LC}^{*+} \\
\mathrm{H}^{*+}\end{array}$ & $\begin{array}{c}\text { E+ } \\
\text { LC }^{*} \\
\mathrm{H}^{*}\end{array}$ & $\begin{array}{l}\text { E+ } \\
\text { LC* } \\
\text { H+ }\end{array}$ & $\begin{array}{c}\mathrm{E}^{*+} \\
\mathrm{LC}^{*} \\
+\mathrm{H}^{*+}\end{array}$ & $\begin{array}{c}\mathrm{E}^{*+} \\
\mathrm{LC}^{*+} \\
\mathrm{H}_{+}^{*}\end{array}$ & $\begin{array}{c}\mathrm{E}^{*+} \\
\mathrm{LC}^{*+} \\
\mathrm{H}^{*+}\end{array}$ \\
\hline & First generation biofuels $^{19}$ & Yes & No & Yes & Yes & Yes & Yes & Yes & Yes & Yes & Yes \\
\hline & Vehicle cost & $\mathrm{D}$ & $\mathrm{X}$ & $\mathrm{X}$ & $\mathrm{D}$ & $\mathrm{X}$ & $\mathrm{x}$ & $\mathrm{D}$ & $\mathrm{X}$ & No & $\mathrm{D}$ \\
\hline & Vehicle efficiency & $\mathrm{D}$ & $\mathrm{x}$ & $\mathrm{x}$ & $\mathrm{X}$ & $\mathrm{X}$ & $\mathrm{x}$ & $\mathrm{D}$ & $\mathrm{X}$ & No & $X$ \\
\hline & Technological competition & Logit & Flexible & Flexible & Flexible & Logit & Flexible & Logit & Logit & Flexible & Logit \\
\hline
\end{tabular}

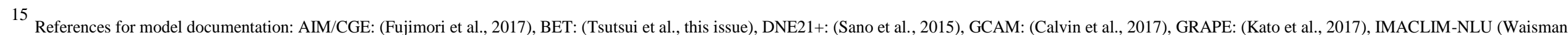
et al., 2012), IMAGE: (van Vuuren et al., 2017), MESSAGE-GLOBIOM: (Fricko et al., 2017), POLES:(Keramidas et al., 2017), REMIND-MAgPIE: (Baeur et al., 2020).

16 Computable general equilibrium (CGE); Partial equilibrium (PE); Recursive-Dynamic (RD); Iterative (IT)

${ }^{17} \mathrm{X}$, stands for exogenous and $\mathrm{D}$ for endogenous. D- means endogenous, but not explicit.

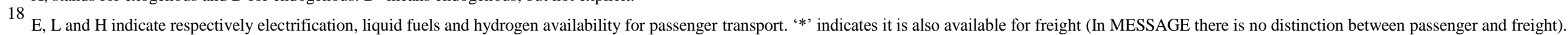

'+' indicates that CCS is available along with energy carrier production from biomass. For GCAM: No electricity nor hydrogen for trucks, but only for trains.
19 First generation biofuels are modelled through cost competition in all models except IMACLIM-NLU and REMIND-MAGPIE, in which exogenous scenarios are prescribed. 


\section{References}

Ahlgren, Erik O., Martin Börjesson Hagberg, and Maria Grahn. 2017. "Transport Biofuels in Global Energy-Economy Modelling - a Review of Comprehensive Energy Systems Assessment Approaches.” GCB Bioenergy 9 (7): 1168-80.

Azar, C., Lindgren, K., Obersteiner, M. et al. The feasibility of low $\mathrm{CO}_{2}$ concentration targets and the role of bio-energy with carbon capture and storage (BECCS). Climatic Change 100, 195202 (2010). https://doi.org/10.1007/s10584-010-9832-7

Bauer, N., Klein, D., Humpenöder, F., Kriegler, E., Luderer, G., Popp, A., Strefler, J., 2020. Bioenergy and $\mathrm{CO} 2$ emission reductions: an integrated land-use and energy sector perspective. Climatic Change, 163, 1675-1693. https://doi.org/10.1007/s10584-020-02895-Z.

Bauer, Nico, Steven K. Rose, Shinichiro Fujimori, Detlef P. van Vuuren, John Weyant, Marshall Wise, Yiyun Cui, et al. 2018. "Global Energy Sector Emission Reductions and Bioenergy Use: Overview of the Bioenergy Demand Phase of the EMF-33 Model Comparison." Climatic Change, July. https://doi.org/10.1007/s10584-018-2226-y.

Calvin, Katherine, Ben Bond-Lamberty, Leon Clarke, James Edmonds, Jiyong Eom, Corinne Hartin, Sonny Kim, et al. 2017. "The SSP4: A World of Deepening Inequality." Global Environmental Change 42 (January): 284-96. https://doi.org/10.1016/j.gloenvcha.2016.06.010.

Cheah, Wai Yan, Tau Chuan Ling, Joon Ching Juan, Duu-Jong Lee, Jo-Shu Chang, and Pau Loke Show. 2016. "Biorefineries of Carbon Dioxide: From Carbon Capture and Storage (CCS) to Bioenergies Production.” Bioresource Technology 215 (September): 346-56. https://doi.org/10.1016/j.biortech.2016.04.019.

Clarke, Leon, Kejun Jiang, Keigo Akimoto, Mustafa Babiker, Geoffrey Blanford, Karen FisherVanden, Jean-Charles Hourcade, et al. 2014. "Assessing Transformation Pathways." In Climate Change 2014: Mitigation of Climate Change. Contribution of Working Group III to the Fifth Assessment Report of the Intergovernmental Panel on Climate Change [Edenhofer, O., R. Pichs-Madruga, Y. Sokona, E. Farahani, S. Kadner, K. Seyboth, A. Adler, I. Baum, S. Brunner, P. Eickemeier, B. Kriemann, J. Savolainen, S. Schlömer, C. von Stechow, T. Zwickel and J.C. Minx (Eds.)]. Cambridge University Press, Cambridge, United Kingdom and New York, NY, USA. 
Creutzig, F., P. Jochem, O. Y. Edelenbosch, L. Mattauch, D. P. v. Vuuren, D. McCollum, and J. Minx. 2015. “Transport: A Roadblock to Climate Change Mitigation?” Science 350 (6263): 911-912. https://doi.org/10.1126/science.aac8033.

Daioglou, Vassilis, Jonathan C. Doelman, Elke Stehfest, Christoph Müller, Birka Wicke, Andre Faaij, and Detlef P. van Vuuren. 2017. "Greenhouse Gas Emission Curves for Advanced Biofuel Supply Chains.” Nature Climate Change 7 (12): 920-24. https://doi.org/10.1038/s41558-017-0006-8.

Daioglou, Vassilis, Steven K Rose, Nico Bauer, Alban Kitous, Matteo Muratori, Shinichiro Fujimori, Matthew Gidden, et al. 2020. "Bioenergy Technologies in Long-Run Climate Change Mitigation: Results from the EMF-33 Study.”. Climatic Change (August). https://doi.org/10.1007/s10584-020-02799-y.

Du, Xiaodong, and Miguel A. Carriquiry. 2013. "Flex-Fuel Vehicle Adoption and Dynamics of Ethanol Prices: Lessons from Brazil.” Energy Policy 59 (August): 507-12.

https://doi.org/10.1016/j.enpol.2013.04.008.

Edelenbosch, O.Y., D.L. McCollum, D.P. van Vuuren, C. Bertram, S. Carrara, H. Daly, S. Fujimori, et al. 2017. "Decomposing Passenger Transport Futures: Comparing Results of Global Integrated Assessment Models.” Transportation Research Part D: Transport and Environment 55: 281-293. https://doi.org/10.1016/j.trd.2016.07.003.

Elgowainy, A., Han, J., Ward, J., Joseck, F., Gohlke, D., Lindauer, A., Ramsden, T., Biddy, M., Alexander, M., Barnhart, S., Sutherland, I., Verduzco, L., Wallington, T.J., 2018. Current and Future United States Light-Duty Vehicle Pathways: Cradle-to-Grave Lifecycle Greenhouse Gas Emissions and Economic Assessment. Environ. Sci. Technol. 52, 2392-2399. https://doi.org/10.1021/acs.est.7b06006.

Fajardy, Mathilde, and Niall Mac Dowell. 2017. "Can BECCS Deliver Sustainable and Resource Efficient Negative Emissions?” Energy Environ. Sci. 10 (6): 1389-1426.

https://doi.org/10.1039/C7EE00465F.

Fricko, Oliver, Petr Havlik, Joeri Rogelj, Zbigniew Klimont, Mykola Gusti, Nils Johnson, Peter Kolp, et al. 2017. "The Marker Quantification of the Shared Socioeconomic Pathway 2: A Middle-of-the-Road Scenario for the 21st Century." Global Environmental Change 42 (January): 251-67. https://doi.org/10.1016/j.gloenvcha.2016.06.004.

Fujimori, Shinichiro, Tomoko Hasegawa, Toshihiko Masui, Kiyoshi Takahashi, Diego Silva Herran, Hancheng Dai, Yasuaki Hijioka, and Mikiko Kainuma. 2017. “SSP3: AIM 
Implementation of Shared Socioeconomic Pathways.” Global Environmental Change 42 (January): 268-83. https://doi.org/10.1016/j.gloenvcha.2016.06.009.

Fuss, Sabine, William F Lamb, Max W Callaghan, Jérôme Hilaire, Felix Creutzig, Thorben Amann, Tim Beringer, et al. 2018. "Negative Emissions_-Part 2: Costs, Potentials and Side Effects." Environmental Research Letters 13 (6): 063002. https://doi.org/10.1088/1748-9326/aabf9f.

Fuss, Sabine, et al. "Betting on negative emissions." Nature climate change 4.10 (2014): 850-853.

Gota, Sudhir, Cornie Huizenga, Karl Peet, Nikola Medimorec, and Stefan Bakker. 2019. “Decarbonising Transport to Achieve Paris Agreement Targets.” Energy Efficiency 12 (2): 363-86. https://doi.org/10.1007/s12053-018-9671-3.

Havlík, Petr, Uwe A. Schneider, Erwin Schmid, Hannes Böttcher, Steffen Fritz, Rastislav Skalský, Kentaro Aoki, et al. 2011. "Global Land-Use Implications of First and Second Generation Biofuel Targets.” Energy Policy 39 (10): 5690-5702.

https://doi.org/10.1016/j.enpol.2010.03.030.

Hileman, J.I., and R.W. Stratton. 2014. “Alternative Jet Fuel Feasibility.” Transport Policy 34 (July): 52-62. https://doi.org/10.1016/j.tranpol.2014.02.018.

IPCC. 2013. Climate Change 2013: The Physical Science Basis. Contribution of Working Group I to the Fifth Assessment Report of the Intergovernmental Panel on Climate Change. Cambridge, United Kingdom and New York, NY, USA: Cambridge University Press. Www.climatechange2013.org.

International Energy Agency, 2017. Delivering Sustainable Bioenergy. https://doi.org/10.1787/9789264287600-en.

International Energy Agency. 2019. CO2 Emissions from Fuel Combustion 2019. CO2 Emissions from Fuel Combustion. OECD. https://doi.org/10.1787/2a701673-en.

International Energy Agency, 2020a. World Energy outlook 2020

International Energy Agency, 2020b, Global EV Outlook 2020, IEA, Paris.

\section{https://www.iea.org/reports/global-ev-outlook-2020}

Johnson, Nils, Nathan Parker, and Joan Ogden. 2014. "How Negative Can Biofuels with CCS Take Us and at What Cost? Refining the Economic Potential of Biofuel Production with CCS Using Spatially-Explicit Modeling.” Energy Procedia 63: 6770-91. https://doi.org/10.1016/j.egypro.2014.11.712. 
Kato, Etsushi, Ryo Moriyama, and Atsushi Kurosawa. 2017. “A Sustainable Pathway of Bioenergy with Carbon Capture and Storage Deployment.” Energy Procedia 114 (July): 6115-23. https://doi.org/10.1016/j.egypro.2017.03.1748.

Kavitha, C., and Vijayasarathi Prabakaran. 2015. "An Overview of Corrosion Performance of Automotive Metals in Biodiesel." Research Journal of Engineering and Technology 6 (January): 457. https://doi.org/10.5958/2321-581X.2015.00071.9.

Keramidas, Kimon, Alban Kitous, Jacques Després, Andreas Schmitz, Ana Diaz Vazquez, Silvana Mima, Peter Russ, and Tobias Wiesenthal. 2017. "POLES-JRC Model Documentation.” JRC Working Papers JRC107387. Joint Research Centre (Seville site). https://EconPapers.repec.org/RePEc:ipt:iptwpa:jrc107387.

Kriegler, Elmar, John P. Weyant, Geoffrey J. Blanford, Volker Krey, Leon Clarke, Jae Edmonds, Allen Fawcett, et al. 2014. "The Role of Technology for Achieving Climate Policy Objectives: Overview of the EMF 27 Study on Global Technology and Climate Policy Strategies." Climatic Change 123 (3-4): 353-367. https://doi.org/10.1007/s10584-013-09537.

Leblanc, Florian, Thierry Brunelle, Patrice Dumas, Ruben Bibas, Chloe Pelletier, and Rémy Prudhomme. This issue. "Trade-offs across energy sectors in using biomass for climate change mitigation: an integrated assessment with Imaclim-NLU."

Li, Wei, Chao Yue, Philippe Ciais, Jinfeng Chang, Daniel Goll, Dan Zhu, Shushi Peng, and Albert Jornet-Puig. 2018. “ORCHIDEE-MICT-BIOENERGY: An Attempt to Represent the Production of Lignocellulosic Crops for Bioenergy in a Global Vegetation Model." Geoscientific Model Development 11 (6): 2249-72. https://doi.org/10.5194/gmd-11-22492018.

Lotze-Campen, Hermann, Martin von Lampe, Page Kyle, Shinichiro Fujimori, Petr Havlik, Hans van Meijl, Tomoko Hasegawa, et al. 2014. "Impacts of Increased Bioenergy Demand on Global Food Markets: An AgMIP Economic Model Intercomparison.” Agricultural Economics 45 (1): 103-16. https://doi.org/10.1111/agec.12092.

Low, S. and Schäfer, S., 2020. Is bio-energy carbon capture and storage (BECCS) feasible? The contested authority of integrated assessment modeling. Energy Research \& Social Science, 60, p.101326.

Sean, Low and Stefan Schäfer Stefan 2020. "Is bio-energy carbon capture and storage (BECCS) feasible? The contested authority of integrated assessment modeling." Energy Research \& Social Science (60). https://doi.org/10.1016/j.erss.2019.101326.Luderer, Gunnar, Zoi 
Vrontisi, Christoph Bertram, Oreane Y. Edelenbosch, Robert C. Pietzcker, Joeri Rogelj, Harmen Sytze De Boer, et al. 2018. "Residual Fossil CO2 Emissions in 1.5-2 ${ }^{\circ} \mathrm{C}$ Pathways." Nature Climate Change 8 (7): 626-33. https://doi.org/10.1038/s41558-018-0198-6.

Macedo, I.C., Nassa, A.M., Cowie, A.L. Seabra, J.E.A., Marelli, L., Otto, M., Wang, M.Q., Tyner, E., 2014. "Greenhouse gas emissions from bioenergy", in G. Souza (eds.), Bioenergy and Sustainability: Bridging the Gaps, report commissioned by SCOPE - Scientific Committee on Problems of the Environment.

Mai, Trieu, Paige Jadun, Jeffrey Logan, Colin McMillan, Matteo Muratori, Daniel Steinberg, Laura Vimmerstedt, Ryan Jones, Benjamin Haley, and Brent Nelson. 2018. Electrification Futures Study: Scenarios of Electric Technology Adoption and Power Consumption for the United States. Golden, CO: National Renewable Energy Laboratory. NREL/TP-6A20-71500. https://www.nrel.gov/docs/fy180sti/71500.pdf.

Marangoni, G., M. Tavoni, V. Bosetti, E. Borgonovo, P. Capros, O. Fricko, D. E. H. J. Gernaat, et al. 2017. "Sensitivity of Projected Long-Term CO2 Emissions across the Shared Socioeconomic Pathways." Nature Climate Change 7 (2): 113-17. https://doi.org/10.1038/nclimate3199.

McCollum, David L., Charlie Wilson, Hazel Pettifor, Kalai Ramea, Volker Krey, Keywan Riahi, Christoph Bertram, Zhenhong Lin, Oreane Y. Edelenbosch, and Sei Fujisawa. 2017. "Improving the Behavioral Realism of Global Integrated Assessment Models: An Application to Consumers' Vehicle Choices.” Transportation Research Part D: Transport and Environment 55 (August): 322-42. https://doi.org/10.1016/j.trd.2016.04.003.

McCollum, David, Volker Krey, Peter Kolp, Yu Nagai, and Keywan Riahi. 2014. "Transport Electrification: A Key Element for Energy System Transformation and Climate Stabilization." Climatic Change 123 (3-4): 651-64. https://doi.org/10.1007/s10584-013-0969-z.

Mercure, J.-F., A. Lam, S. Billington, and H. Pollitt. 2018. "Integrated Assessment Modelling as a Positive Science: Private Passenger Road Transport Policies to Meet a Climate Target Well below 2 oC." Climatic Change 151 (2): 109-29. https://doi.org/10.1007/s10584-018-2262-7. Mulholland, Eamonn, Jacob Teter, Pierpaolo Cazzola, Zane McDonald, and Brian P. Ó Gallachóir. 2018. "The Long Haul towards Decarbonising Road Freight - A Global Assessment to 2050." Applied Energy 216 (April): 678-93. https://doi.org/10.1016/j.apenergy.2018.01.058.

Muratori, M., Mai, T., 2021. The shape of electrified transportation. Environ. Res. Lett. 16, 011003. https://doi.org/10.1088/1748-9326/abcb38. 
Muratori, M., Bauer, N., Rose, S.K., Wise, M., Daioglou, V., Cui, Y., Kato, E., Gidden, M., Strefler, J., Fujimori, S. and Sands, R.D., 2020a. EMF-33 insights on bioenergy with carbon capture and storage (BECCS). Climatic Change, 163(3), pp.1621-1637.

Muratori, M., Jadun, P., Bush, B., Bielen, D., Vimmerstedt, L., Gonder, J., Gearhart, C. and Arent, D., 2020b. Future integrated mobility-energy systems: A modeling perspective. Renewable and Sustainable Energy Reviews, 119, p.109541.

Muratori, Matteo, Haroon Kheshgi, Bryan Mignone, Leon Clarke, Haewon McJeon, and Jae Edmonds. 2017a. "Carbon Capture and Storage across Fuels and Sectors in Energy System Transformation Pathways.” International Journal of Greenhouse Gas Control 57 (February): 34-41. https://doi.org/10.1016/j.ijggc.2016.11.026.

Muratori, M., Smith, S.J., Kyle, P., Link, R., Mignone, B.K. and Kheshgi, H.S., 2017b. "Role of the freight sector in future climate change mitigation scenarios." Environmental science \& technology, 51(6), pp.3526-3533. https://pubs.acs.org/doi/abs/10.1021/acs.est.6b04515.

Muratori, M., Calvin, K., Wise, M., Kyle, P. and Edmonds, J., 2016. Global economic consequences of deploying bioenergy with carbon capture and storage (BECCS). Environmental Research Letters, 11(9), p.095004.

Nadel, Steven. 2019. "Electrification in the Transportation, Buildings, and Industrial Sectors: A Review of Opportunities, Barriers, and Policies." Current Sustainable/Renewable Energy Reports 6 (4): 158-68. https://doi.org/10.1007/s40518-019-00138-z.

Ramea, Kalai, David S. Bunch, Christopher Yang, Sonia Yeh, and Joan M. Ogden. 2018. "Integration of Behavioral Effects from Vehicle Choice Models into Long-Term Energy Systems Optimization Models.” Energy Economics 74 (August): 663-76. https://doi.org/10.1016/j.eneco.2018.06.028.

Realmonte, G., Drouet, L., Gambhir, A., Glynn, J., Hawkes, A., Köberle, A. C., and Tavoni, M. 2019. "An inter-model assessment of the role of direct air capture in deep mitigation pathways". Nature Communications, 10(1):3277. https://doi.org/10.1038/s41467-019-10842$\underline{5}$

Riahi, Keywan, Detlef P. van Vuuren, Elmar Kriegler, Jae Edmonds, Brian C. O’Neill, Shinichiro Fujimori, Nico Bauer, et al. 2017. "The Shared Socioeconomic Pathways and Their Energy, Land Use, and Greenhouse Gas Emissions Implications: An Overview.” Global Environmental Change 42 (January): 153-168. https://doi.org/10.1016/j.gloenvcha.2016.05.009. 
Rogelj, Joeri, Gunnar Luderer, Robert C. Pietzcker, Elmar Kriegler, Michiel Schaeffer, Volker Krey, and Keywan Riahi. 2015. "Energy System Transformations for Limiting End-ofCentury Warming to below $1.5^{\circ} \mathrm{C}$." Nature Climate Change 5 (6): 519-527. https://doi.org/10.1038/nclimate2572.

Rogelj, Joeri, Michiel Schaeffer, Pierre Friedlingstein, Nathan P. Gillett, Detlef P. van Vuuren, Keywan Riahi, Myles Allen, and Reto Knutti. 2016. "Differences between Carbon Budget Estimates Unravelled." Nature Climate Change 6 (3): 245-52. https://doi.org/10.1038/nclimate2868.

Rogelj, J., D. Shindell, K. Jiang, S. Fifita, P. Forster, V. Ginzburg, C. Handa, et al. 2018. "Mitigation Pathways Compatible with $1.5^{\circ} \mathrm{C}$ in the Context of Sustainable Development." In Global Warming of $1.5^{\circ} \mathrm{C}$. An IPCC Special Report on the Impacts of Global Warming of $1.5^{\circ} \mathrm{C}$ above Pre-Industrial Levels and Related Global Greenhouse Gas Emission Pathways, in the Context of Strengthening the Global Response to the Threat of Climate Change, Sustainable Development, and Efforts to Eradicate Poverty, edited by V. Masson-Delmotte, P. Zhai, H.O. Pörtner, D. Roberts, J. Skea, P.R. Shukla, A. Pirani, et al., 93-174. In Press. Rose, S.K., Bauer, N., Popp, A. et al. An overview of the Energy Modeling Forum 33rd study: assessing large-scale global bioenergy deployment for managing climate change. Climatic Change 163, 1539-1551 (2020). https://doi.org/10.1007/s10584-020-02945-6

Rose, Steven K., Elmar Kriegler, Ruben Bibas, Katherine Calvin, Alexander Popp, Detlef P. van Vuuren, and John Weyant. 2013. "Bioenergy in Energy Transformation and Climate Management." Climatic Change, 1-17.

Rose, Steven K, Alexander Popp, Shinichiro Fujimori, Petr Havlik, Detlef P van Vuuren, John Weyant, and Marshall Wise. This issue. "Global Biomass Supply Modeling for Long-Run Management of the Climate System."

Sano, Fuminori, Kenichi Wada, Keigo Akimoto, and Junichiro Oda. 2015. "Assessments of GHG Emission Reduction Scenarios of Different Levels and Different Short-Term Pledges through Macro- and Sectoral Decomposition Analyses." Technological Forecasting and Social Change 90: 153-65. https://doi.org/10.1016/j.techfore.2013.11.002.

Schultres, A., Leimbach, M., Luderer, G., Pietzcker, R.C., Baumstark, L., Bauer, N., Kriegler, E., Edenhofer, O., 2018. Optimal international technology cooperation for the low-carbon transformation. Climate Policy 18, 1165-1176. https://doi.org/10.1080/14693062.2017.1409190 
Sims, Ralph, Roberto Schaeffer, Felix Creutzig, Xochitl Cruz-Núñez, Marcio D’Agosto, Dalia Dimitriu, Maria Josefina Figueroa Meza, et al. 2014. “Transport." In Climate Change 2014: Mitigation of Climate Change. Contribution of Working Group III to the Fifth Assessment Report of the Intergovernmental Panel on Climate Change [Edenhofer, O., R. PichsMadruga, Y. Sokona, E. Farahani, S. Kadner, K. Seyboth, A. Adler, I. Baum, S. Brunner, P. Eickemeier, B. Kriemann, J. Savolainen, S. Schlömer, C. von Stechow, T. Zwickel and J.C. Minx (Eds.)]. Cambridge University Press, Cambridge, United Kingdom and New York, NY, USA.

Singh, B., John Korstad, and Y.C. Sharma. 2012. "A Critical Review on Corrosion of Compression Ignition (CI) Engine Parts by Biodiesel and Biodiesel Blends and Its Inhibition." Renewable and Sustainable Energy Reviews 16 (5): 3401-8. https://doi.org/10.1016/j.rser.2012.02.042.

Sorate, Kamalesh A., and Purnanand V. Bhale. 2015. "Biodiesel Properties and Automotive System Compatibility Issues.” Renewable and Sustainable Energy Reviews 41 (January): 777-98. https://doi.org/10.1016/j.rser.2014.08.079.

Stoy, Paul C, Selena Ahmed, Meghann Jarchow, Benjamin Rashford, David Swanson, Shannon Albeke, Gabriel Bromley, et al. 2018. "Opportunities and Trade-Offs among BECCS and the Food, Water, Energy, Biodiversity, and Social Systems Nexus at Regional Scales.” BioScience 68 (2): 100-111. https://doi.org/10.1093/biosci/bix145.

Taljegard, Maria, Selma Brynolf, Maria Grahn, Karin Andersson, and Hannes Johnson. 2014. "Cost-Effective Choices of Marine Fuels in a Carbon-Constrained World: Results from a Global Energy Model.” Environmental Science \& Technology 48 (21): 12986-93. https://doi.org/10.1021/es5018575.

Tanzer, Samantha Eleanor, John Posada, Sjors Geraedts, and Andrea Ramírez. 2019. "Lignocellulosic Marine Biofuel: Technoeconomic and Environmental Assessment for Production in Brazil and Sweden.” Journal of Cleaner Production 239 (December): 117845. https://doi.org/10.1016/j.jclepro.2019.117845.

Transports, Forum International des. 2018. "Decarbonising Maritime Transport," no. 47. https://doi.org/10.1787/b1a7632c-en.

Tsutsui, J., H. Yamamoto, S. Sakamoto, and M. Sugiyama. 2020. "The role of advanced end-use technologies in long-term climate change mitigation: the interlinkage between primary bioenergy and energy end-use," Climatic Change, 163, 1675-1693. https://doi.org/10.1007/s10584-020-02839-7. 
van Vuuren, Detlef P., Elke Stehfest, David E.H.J. Gernaat, Jonathan C. Doelman, Maarten van den Berg, Mathijs Harmsen, Harmen Sytze de Boer, et al. 2017. "Energy, Land-Use and Greenhouse Gas Emissions Trajectories under a Green Growth Paradigm.” Global Environmental Change 42 (January): 237-50.

https://doi.org/10.1016/j.gloenvcha.2016.05.008.

Venturini, Giada, Jacopo Tattini, Eamonn Mulholland, and Brian Ó Gallachóir. 2019. "Improvements in the Representation of Behavior in Integrated Energy and Transport Models." International Journal of Sustainable Transportation 13 (4): 294-313. https://doi.org/10.1080/15568318.2018.1466220.

Victor, David Gardiner, Dadi Zhou, Essam Hassan Mohamed Ahmed, Pradeep Kumar Dadhich, Jos Gerardus Jozef Olivier, Hans-Holger Rogner, Kamel Sheikho, and Mitsutsune Yamaguchi. 2014. "Introductory Chapter." In Climate Change 2014: Mitigation of Climate Change. Contribution of Working Group III to the Fifth Assessment Report of the Intergovernmental Panel on Climate Change [Edenhofer, O., R. Pichs-Madruga, Y. Sokona, E. Farahani, S. Kadner, K. Seyboth, A. Adler, I. Baum, S. Brunner, P. Eickemeier, B. Kriemann, J. Savolainen, S. Schlömer, C. von Stechow, T. Zwickel and J.C. Minx (Eds.)]. Cambridge University Press, Cambridge, United Kingdom and New York, NY, USA.

Waisman, Henri, Céline Guivarch, Fabio Grazi, and Jean Charles Hourcade. 2012. "The Imaclim-R Model: Infrastructures, Technical Inertia and the Costs of Low Carbon Futures under Imperfect Foresight." Climatic Change 114 (1): 101-20. https://doi.org/10.1007/s10584-0110387-z.

Wei, Hongjian, Wenzhi Liu, Xinyu Chen, Qing Yang, Jiashuo Li, and Hanping Chen. 2019. "Renewable Bio-Jet Fuel Production for Aviation: A Review." Fuel 254 (October): 115599. https://doi.org/10.1016/j.fuel.2019.06.007.

Wise, Marshall, Matteo Muratori, and Page Kyle. 2017. "Biojet Fuels and Emissions Mitigation in Aviation: An Integrated Assessment Modeling Analysis." Transportation Research Part D: Transport and Environment 52: 244-53. https://doi.org/10.1016/j.trd.2017.03.006.

Why, Elaine Siew Kuan, Hwai Chyuan Ong, Hwei Voon Lee, Yong Yang Gan, Wei-Hsin Chen, and Cheng Tung Chong. 2019. "Renewable Aviation Fuel by Advanced Hydroprocessing of Biomass: Challenges and Perspective.” Energy Conversion and Management 199 (November): 112015. https://doi.org/10.1016/j.enconman.2019.112015.Yeh, Sonia, Gouri Shankar Mishra, Lew Fulton, Page Kyle, David L. McCollum, Joshua Miller, Pierpaolo 
Cazzola, and Jacob Teter. 2017. “Detailed Assessment of Global Transport-Energy Models' Structures and Projections." Transportation Research Part D: Transport and Environment 55 (August): 294-309. https://doi.org/10.1016/j.trd.2016.11.001.

Yeh, Sonia, Gouri Shankar Mishra, Lew Fulton, Page Kyle, David L. McCollum, Joshua Miller, Pierpaolo Cazzola, and Jacob Teter. 2017. "Detailed Assessment of Global Transport-Energy Models' Structures and Projections." Transportation Research Part D: Transport and Environment 55 (August): 294-309. https://doi.org/10.1016/j.trd.2016.11.001.

Zhang, Runsen, and Shinichiro Fujimori. 2020. "The Role of Transport Electrification in Global Climate Change Mitigation Scenarios.” Environmental Research Letters 15 (3): 034019. https://doi.org/10.1088/1748-9326/ab6658.

Zhang, Runsen, Shinichiro Fujimori, Hancheng Dai, and Tatsuya Hanaoka. 2018. "Contribution of the Transport Sector to Climate Change Mitigation: Insights from a Global Passenger Transport Model Coupled with a Computable General Equilibrium Model.” Applied Energy 211 (February): 76-88. https://doi.org/10.1016/j.apenergy.2017.10.103. 